\title{
Notas codicológicas sobre algunos testimonios de las Siete Partidas ${ }^{1}$
}

\section{Codicological notes about some Siete Partidas'witnesses}

José Manuel Fradejas Rueda josemanuel.fradejas@uva.es

Universidad de Valladolid, España

Recepción: 23 Abril 2021

Aprobación: 09 Agosto 2021

Publicación: 01 Noviembre 2021

Cita sugerida: Fradejas Rueda, J. M. (2021). Notas codicológicas sobre algunos testimonios de las Siete Partidas. Olivar, 21(34), e103. https://doi.org/10.24215/18524478e103
Resumen: El deber básico de todo investigador que aborde la edición de un texto con transmisión manuscrita, e incluso impresa, es el examen directo de todos los testimonios. Alberto Blecua indicaba, también, que "son sumamente importantes las descripciones (...) antiguas de manuscritos” (1983, p. 38). El trabajo de campo realizado en las bibliotecas y archivos que conservan algún testimonio de las Siete Partidas y el análisis de muchas de las viejas descripciones nos han mostrado que se han de tomar con cierta prevención debido a la poca atención que se le ha prestado tanto al soporte material como al contenido de esos testimonios. Producto de la revisión y análisis directo de los originales son las tres notas codicólogicas siguientes. En la primera, se establece que una copia manuscrita conservada en el Archivo Histórico de la Nobleza (Toledo) está basada en un ejemplar de la edición incunable de Díaz Montalvo (1491). En la segunda se demuestra que la tabla inicial del ms. VITR/4/6 de la BNE no está desplazada y que se reubicó en ese lugar cuando se creó el volumen definitivo a lo largo de la segunda mitad del siglo xv. En el tercero se demuestra que el ms. 8721 de la BNE contiene una copia completa, pero mutilada de la Séptima Partida.

Palabras clave: Codicología, Descriptus, Manuscritos, Incunable, Siete Partidas.

Abstract: The basic duty of every researcher who deals with the edition of any manuscript text, and even printed, is the direct examination of all the witnesses. Alberto Blecua also indicated that "ancient descriptions (...) of manuscripts are extremely important" (1983, p. 38). The field work carried out in the libraries and archives that preserve the copies of the Siete Partidas and the analysis of many of old descriptions have shown us that they should be used with due caution since little attention was paid in them to the materiality and textual content of those witnesses. These three codicological notes result from the careful collation of old inventories and direct analysis of the originals. In the first section I argue that a manuscript copy held at the Archivo Histórico de la Nobleza (Toledo) is based on Díaz Montalvo's incunabula of the Siete Partidas. The second section shows that the initial table of BNE ms. VITR/4/6 was relocated there when the definitive volume was created and rebound during the second half of the 15 th century. The third note shows that BNE ms. 8721 contains a complete but mutilated copy of the Siete Partidas.

Keywords: Codicology, Manuscripts, Descriptus, Incunabulum, Siete Partidas. 


\section{TN4 Descriptus de Montalvo}

De las Siete Partidas hay varios testimonios que podríamos llamar indirectos ${ }^{2}$ puesto que no son fragmentos de códices, como es el caso de los que se conservan, por ejemplo, en el Archivo de la Real Chancillería de Valladolid (VA1, VA2, VA3, VA4, VA5, VA6), ${ }^{3}$ en el Archivio di Stato di Modena (MOD) o en la National Library of Israel (JNL), sino que se trata de testimonios que contienen el traslado de algunos pasajes, leyes o títulos, de las Siete Partidas realizados con un fin utilitario, ${ }^{4}$ no la reproducción de toda la obra o una parte sustancial de la misma como cuando se copia una única Partida.

Este testimonio, conservado en el Archivo Histórico de la Nobleza (Osuna C4170, D18) copia a lo largo de dos hojas dobladas por la mitad tres leyes de la Segunda Partida: la primera y la última del título 18 (2.18.1 y 2.18.32) y la décima ley del título 29 (2.29.10). Al transcribir y codificar estas tres leyes observamos que al final de 2.18 .32 (fol. 3r), que no está copiada en su totalidad, tan solo los dos tercios iniciales, el copista incluyó esta aclaración:

otras tales palabras como estas palabras como estas | postreras dende do dize avn pusieron mas pone la | ley 28. del mjsmo y titulo y dize al fin por rrazon del vasallaje

\section{FIGURA 1}

TN4 detalle

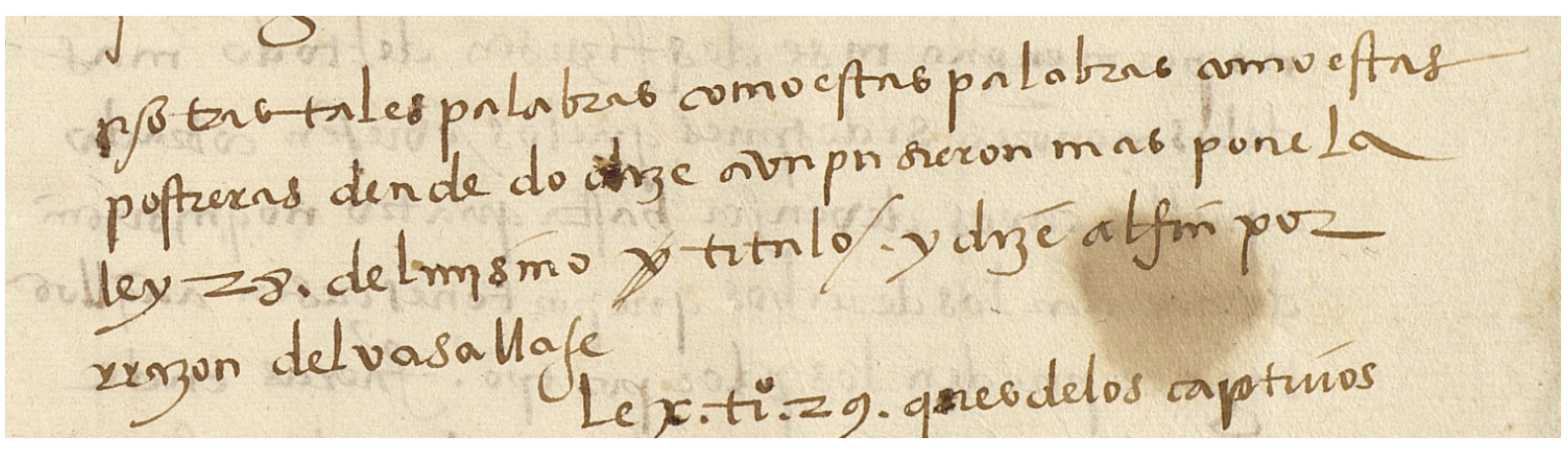

Dado que en las labores iniciales de 7PartidasDigital tomamos la edición de Sánchez-Arcilla (2004, pp. 273-274) como guía rápida de acceso al texto completo de las Siete Partidas, pudimos constatar la veracidad de la afirmación del escriba de TN4, pero, asimismo, comprobamos que no solo había similitud de palabras entre 2.18.32 y 2.18.28 desde "avn pusieron mas" y "por rrazon del vasallaje", como se indica en la nota, sino que la mayor parte de 2.18.28 es idéntica (salvo algunos cambios menores) a 2.18.32. Compulsamos el texto con la edición de López (1555) y la sorpresa es que 2.18.28 es una ley muy breve y que nada tiene del texto que el escribano de TN4 dice que comparte con 2.18.32: 


\begin{tabular}{|c|c|}
\hline 1491 & 1555 \\
\hline 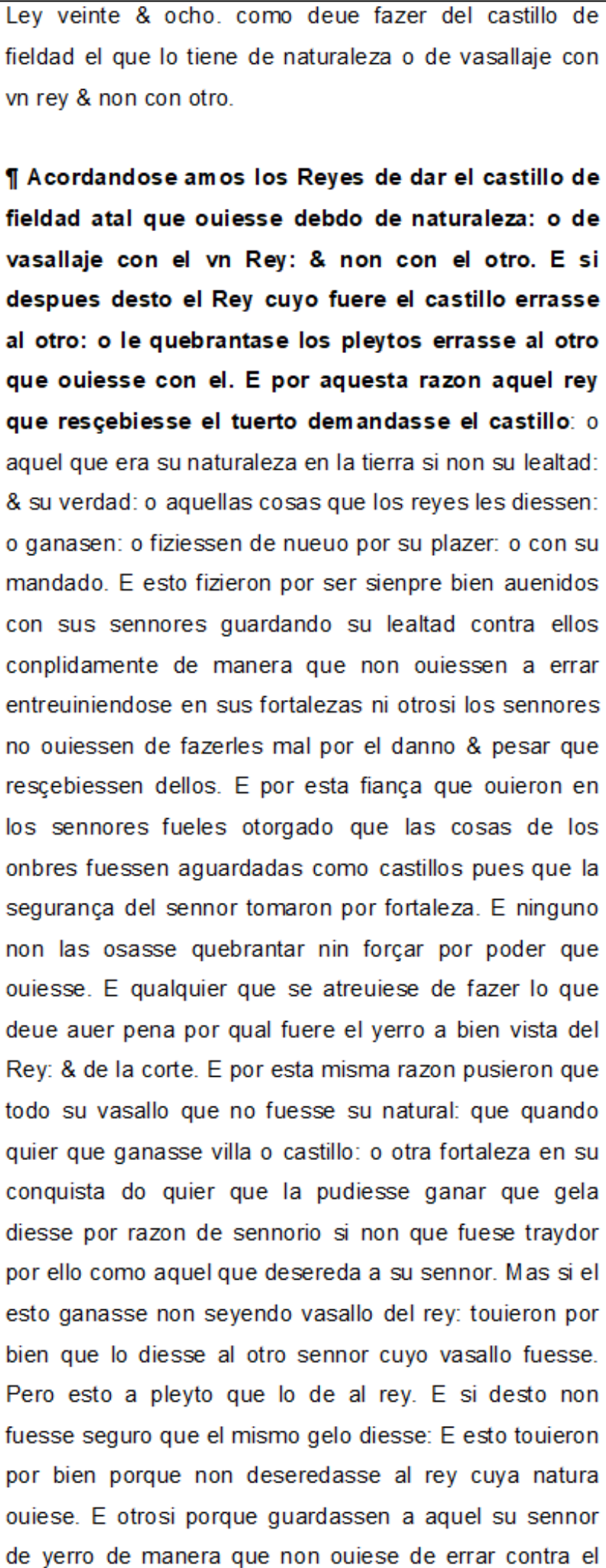 & $\begin{array}{l}\text { T Ley XXVIII. Como deue fazer del castillo de } \\
\text { fieldad, el que lo tiene de naturaleza, o de } \\
\text { vasallaje con vn Rey, e non con otro. } \\
\text { ACordandose am bos los Reyes de dar el } \\
\text { castillo: de fieldad, a tal ome, que ouiesse } \\
\text { debdo, de naturaleza, o de vasallaje, con el } \\
\text { vn Rey, e non con el otro, si despues desto, } \\
\text { el rey cuyo fuere el castillo errasse al otro: e } \\
\text { le quebrantasse los pley tos que ouiesse con } \\
\text { el, e por aquesta razon aquel rey, que } \\
\text { rescibiesse el tuerto, demandasse el } \\
\text { castillo: aquel que era su vassallo o su natural, } \\
\text { con todo esso non gelo deue dar, a menos de } \\
\text { se lo afrontar por su corte al Rey, cuyo es, el } \\
\text { castillo a tres plazos de treinta dias. E si a estos } \\
\text { plazos non le quisiere fazer enmienda, deuele } \\
\text { guerrear tanto de aquel castillo, fasta quel faga } \\
\text { enmienda del daño que fizo a su señor, o quel } \\
\text { mande entregar, de aquel castillo quel } \\
\text { demanda. Ca de otra manera, non lo deue dar, } \\
\text { pues que se fio en el, non seyendo su vassallo, } \\
\text { ni su natural. E si de otra manera diesse el } \\
\text { castillo, faria cosa quel estaria mal, e porque } \\
\text { valdria siempre menos. }\end{array}$ \\
\hline
\end{tabular}




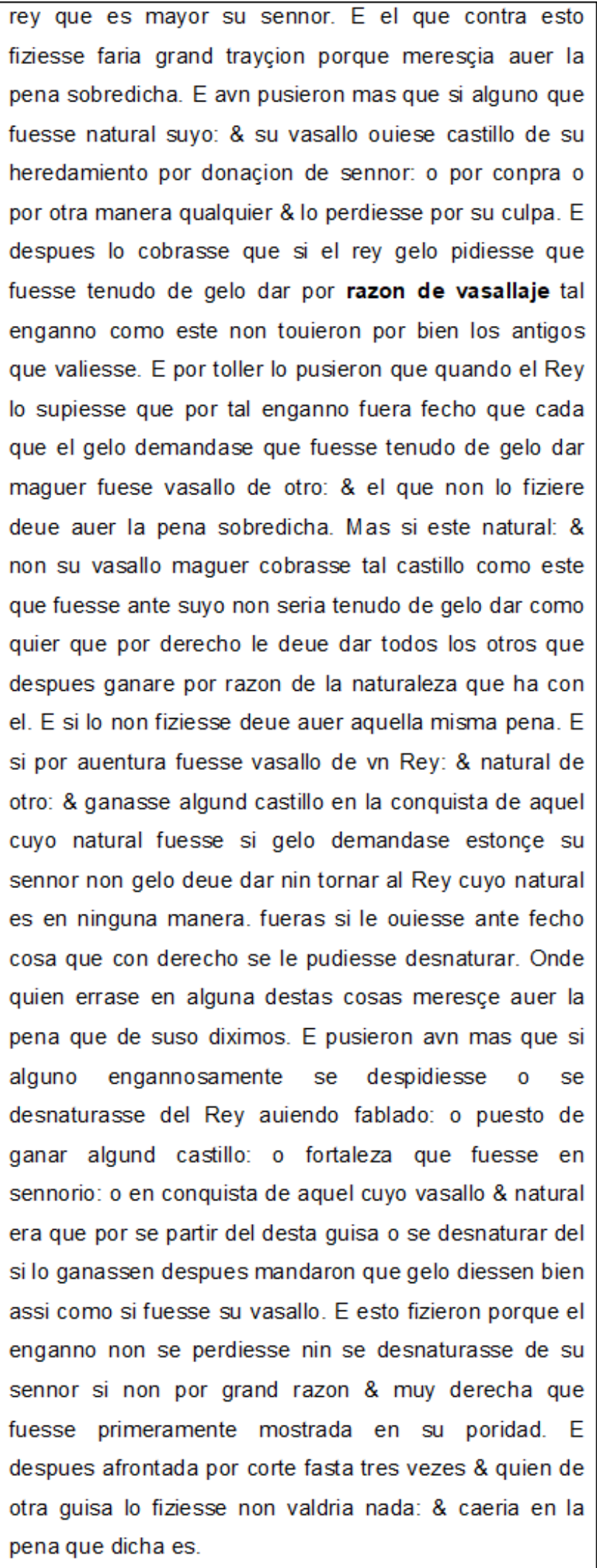


Por consiguiente, podemos establecer que quien extrajo estas tres leyes de la Segunda Partida y las trasladó a los dos bifolios que constituyen TN4 lo hizo teniendo como modelo un ejemplar de la edición de Montalvo, sin que se pueda establecer de cuál ya que no tenemos más elementos para aquilatarlo.

\section{LA TABLA INICIAL DE BNE, VITR/4/6}

El ms. VITR/4/6 de la Biblioteca Nacional de España (BNE) es el único manuscrito completo que se conserva de las Siete Partidas, aunque se trata, en realidad, de un manuscrito facticio construido entre 1458 y $1488 .^{5}$ Esta afirmación se basa en el hecho de que en el folio 6r, en el que se inicia el texto de la Primera Partida (en realidad el prólogo general a las Siete Partidas), se encuentran los escudos de los Estúñiga y los Pimentel / Enríquez y la presencia de las armas de estas dos familias se debe a que don Álvaro de Estúniga casó con Leonor Pimentel y Zúñiga en 1458, lo cual nos ofrece el terminus a quo y 1488 sería el terminus ad quem puesto que en ese año falleció don Álvaro. El grueso de este códice lo constituyen las partidas 2 a 7 (fols. 105r-463v) y, según todas las trazas, es una copia del siglo xiv coloreada, desde el punto de vista lingüístico, del dialecto navarro. En el siglo xv, entre las fechas mencionadas, se hizo una copia de la primera partida (que se saltó todo el contenido, por lo menos, de título tercero) y se encuadernó junto con las otras seis partes en un único volumen que pasó a manos de los Reyes Católicos.

Al encuadernarlo en la casa de los Estúñiga, la persona que se ocupó de ello tuvo el cuidado de tomar un bifolio inicial de la copia del siglo XIV que contenía la tabla de los títulos de las seis partidas que la constituían y situarlo al frente de todo el códice. Sin embargo, varios investigadores (Craddock, 1981, p. 393, n. 48; 1986, p. 53; BETA manid 3373) afirman que ese bifolio está mal encuadernado porque corresponde a la copia del trescientos. No niego este dato, que ese bifolio sea del trescientos y que su ubicación original era al comienzo de la Segunda Partida; lo que sí rechazo es que ese bifolio esté mal situado en el códice que se encuadernó entre 1458 y $1488 .{ }^{6}$ ¿Por qué afirmo que está bien situado?

Sencillamente, creo que el espacio que los copistas del siglo XIV dejaron en blanco en el folio 1r, la primera columna (la de la derecha) y las primeras ocho líneas de la segunda columna se reservó para que una vez completada la copia de las Siete Partidas pudiera ir precedida de una tabla general de títulos para hacer más accesible el texto. Se puede argumentar que es imaginativo pensar que unos copistas del siglo XIV previeron que otros del siglo XV la completarían e introducirían la tabla de los títulos de la Primera Partida. No pretendo tal cosa; es más que probable que cuando se copiaron las restantes Partidas existiera la intención de que el códice recogiera también la Primera Partida, pero quien ordenó (encargó, financió, etc.) esa copia no pudo completar la tarea. 
FIGURA 2

BNE, VITR/4/6, fol. 1. Tabla inicial de Partidas y títulos

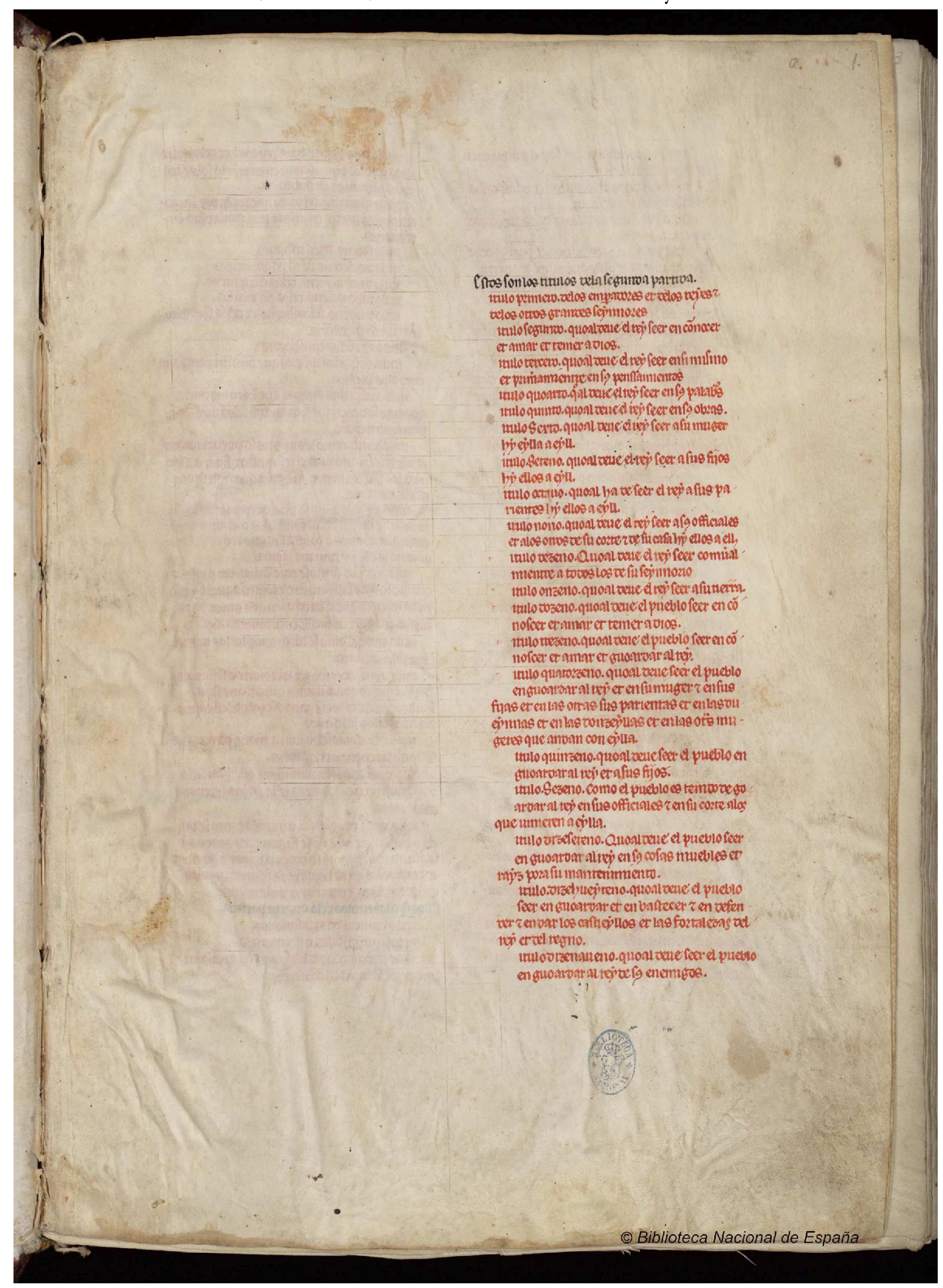


Ahora la siguiente pregunta es: ¿cabría el texto de las rúbricas de los 24 títulos que constituyen la Primera Partida en el espacio reservado? La respuesta es afirmativa: sí se puede acomodar el texto de las rúbricas de esos veinticuatro títulos.

Afortunadamente, el manuscrito ofrece una tabla de los títulos de la Primera Partida en el folio 5v. Este folio, a dos columnas, presenta un pautado de 51 líneas, es decir, un total de 102 líneas. De ellas se utilizaron las diez primeras para copiar el incipit de la obra y, a continuación, y a lo largo de 69 líneas, el texto de las 24 rúbricas. Un sencillo recuento de las líneas dejadas en blanco en el folio 1r para recibir, aparentemente, la tabla de la Primera Partida, descarta esta posibilidad puesto que tan solo hay de 59 líneas disponibles.

FIGURA 3

BNE VITR/4/6, fol. 5. Tabla de títulos de la

\section{Primera Partida}

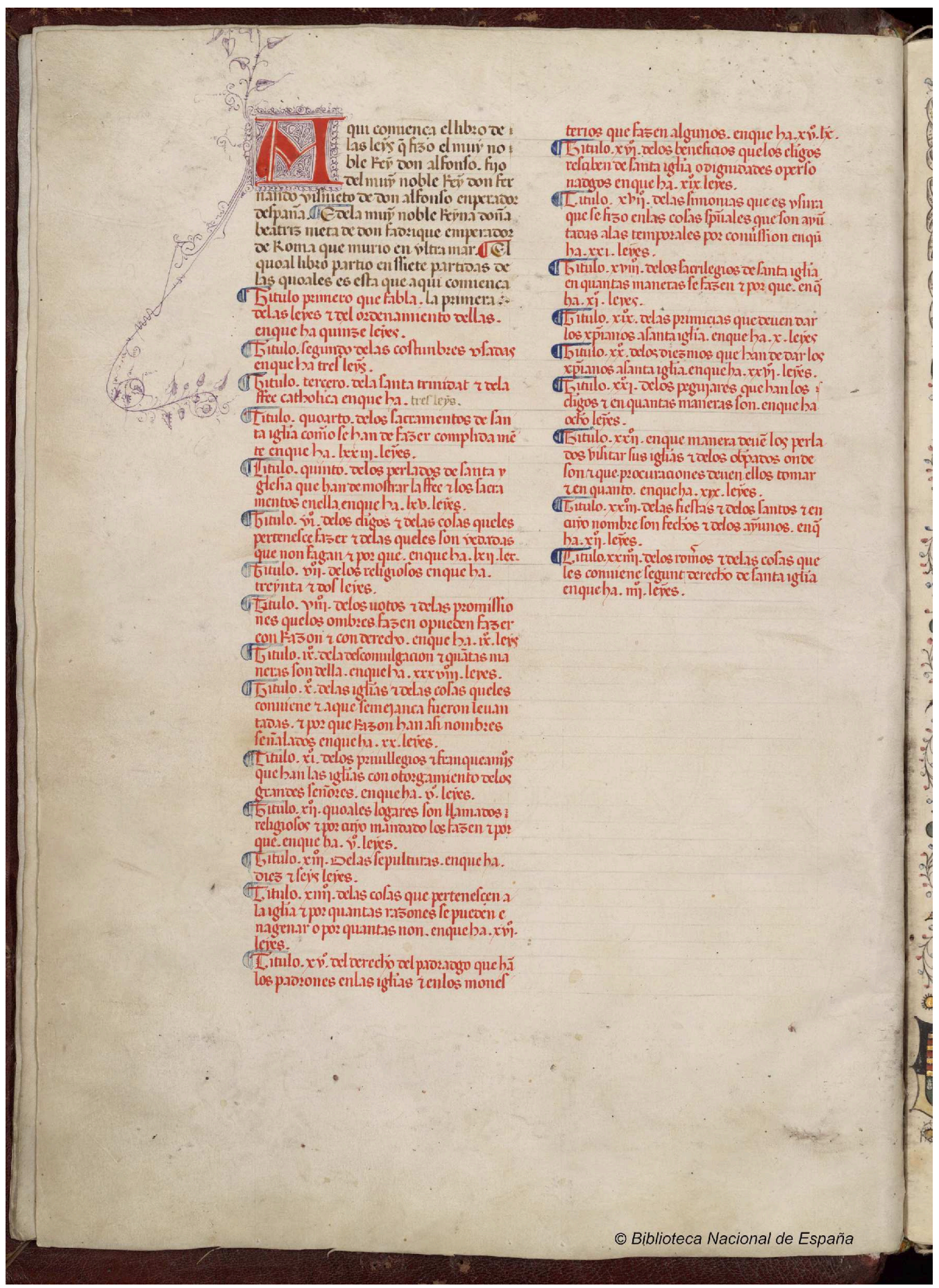


El recuento de los caracteres (13225) que constituyen las diferentes líneas (336, que incluyen el epígrafe (seis casos), en tinta negra, "Estos son los titulos de la partida...") de la tabla de las partidas segunda a séptima permite establecer que la mediana de caracteres por línea es de 44. Por otra parte, la tabla de la Primera Partida está constituida por 2596 caracteres repartidos a lo largo de 69 líneas, lo que proporciona una mediana de 42 caracteres por línea. Es decir, la tabla de títulos de la Primera Partida no cabría en el espacio reservado, pues en las 59 se podrían acomodar tan solo 2478 caracteres y el texto de la tabla del folio $5 \mathrm{v}$ tiene 118 caracteres más.

Sin embargo, la lectura y análisis detenido de la tabla del trescientos y de la tabla de rúbricas de la Primera Partida presenta una interesante diferencia: la tabla de la Primera Partida indica con la expresión "en que ha [número] leyes", lo que no sucede en las tablas para las restantes Partidas. Si se edita la tabla de la Primera Partida, es decir, si se elimina la información referente al número de leyes que constituyen cada título, la longitud de la tabla se reduce a 2055 caracteres, lo que implica una mediana de 41 caracteres por línea, y en este caso sí pueden acomodarse fácilmente, y sobraría espacio, las rúbricas de los veinticuatro títulos de la primera partida.

Por lo tanto, el espacio que los copistas del siglo XIV reservaron en el hoy folio $1 \mathrm{r}$ del ms. VITR/4/6 se dejó con la intención de incluir las rúbricas de los títulos de la Primera Partida y, por consiguiente, el encuadernador del cuatrocientos no erró en la ubicación del bifolio de las tablas. Tan solo olvidaron copiar las rúbricas de la Primera Partida.

\section{¿Extractado o mutilado?}

El MSS/8721 de la BNE, fechado en el siglo XV (según la letra, se puede situar a finales del siglo XIV o principios del siglo XV; la filigrana se asemeja muchísimo a una recogida por Bofarull (1910) tomada de un documento fechado en 1471-72) se describe en los catálogos como que contiene unos extractos de la Séptima Partida alfonsí. Quien lo afirmó tan solo se preocupó de la continuidad lineal del texto y vio que había saltos, pero no se detuvo a ver qué sucedía con la estructura física del códice. Un elemental análisis codicológico le habría descubierto en seguida ciertas peculiaridades que le habrían hecho desistir inmediatamente de la idea de que son extractos, y habría visto que se trataba de una versión completa, aunque mutilada de la Séptima Partida.

Dejemos de lado los dos folios claramente rotos que hay tras el folio 46 (de los que apenas quedan unos jirones de papel) y el hecho de que el manuscrito comienza abruptamente:

quisieren sacar de la tierra contra defendimjento del rrey. Et el segundo es si alguno encubre o furta tributos del rrey, o los derechos del rrey... (MSS/8721, fol. $1 r)$

Esto es casi el comienzo de 7.1.3:

Ley .III. Como aquel que es sieruo non puede acusar a otro.

Contra ninguno non podria fazer acusacion el que fuesse sieruo, si non en casos señalados. El primero seria quando alguno quisiesse acusar a otro en razon de pan, que alguno quisiesse sacar de la tierra contra defendimiento del Rey. El segundo es si alguno encubre, o furta tributos o los derechos del Rey... (López 1555, $7^{a}$ Partida, fol. $3 v$ )

Es evidente que faltan el prólogo introductorio a esta Partida, el proemio al primer título y las dos primeras leyes completas. Esto es un problema bastante frecuente puesto que muchos manuscritos han perdido a lo largo de su vida las primeras hojas por el simple hecho de ser las primeras y estar más expuestas a los vaivenes del uso. Sin embargo, estos dos percances: la pérdida de los dos o tres primeros folios y que otros dos folios interiores hayan sido mutilados, no son motivo para afirmar que el códice contiene tan solo un extracto del texto de la Séptima Partida, porque, de acuerdo con la definición del Diccionario de la lengua española, extracto es un ' $\mathrm{r}$ ] esumen que se hace de un escrito cualquiera, expresando en términos precisos únicamente 
lo más sustancial'. Veamos una de las leyes (7.15.1) y comparémosla con el tenor de acuerdo con la edición de Gregorio López, de 1555, por ser la más conocida y manejada:

\begin{tabular}{|l|l|}
\hline daño es enpeoramjento et menoscabo \& & DAño es empeoramiento o menoscabo, o \\
destruymjento que omne rresçibe en si mjsmo o en & destruymiento que ome rescibe en si mesmo, o en \\
sus cosas por culpa de otro Et son tres maneras & sus cosas por culpa de otro. E son del tres \\
del. La primera es quando se enpeora la cosa por & maneras. La primera es quando se empeora la \\
alguna otra cosa que mezclan con ella o por otro & cosa por alguna otra quel mezclan, o por otro mal \\
mal quel fazen. La segunda es quando se mengua & quel fazen. La segunda, quando se mengua por \\
por rrazon del daño que fazen en ella. La tercera es & razon del daño que fazen en ella. La tercera es, \\
quando la cosa se pierde o se destruye del todo. & quando por el daño se pierde, o se destruye la cosa \\
(BNE, MSS/8721, fol. 42v1) & del todo. (López, 1555, 7a Partida, fol. 56r)
\end{tabular}

Tanto el texto del ms. de la BNE como el texto de López dicen lo mismo y con las mismas palabras, luego no se puede hablar de extracto. Se podría argumentar que el pasaje aportado es muy breve como para perder el tiempo en extractarla. Veamos otro un poco más extenso:

\begin{tabular}{|c|c|}
\hline $\begin{array}{l}\text { Rrebtar puede todo fidalgo por tuerto o desonrra en } \\
\text { que caya trayçion o aleue quel aya fecho otro } \\
\text { fidalgo. E esto puede fazer el por si mjsmo mjentra } \\
\text { fuere bjuo, \& si fuere muerto el que rresçibio la } \\
\text { desonrra puede rrebtar el padre por el fijo, \& el fijo } \\
\text { por el padre, \& el hermano por el hermano. Et si tal } \\
\text { es que parientes non oviere y puedalo fazer el mas } \\
\text { çercano pariente que fincare del muerto, \& avn } \\
\text { puede rresçebir el vasallo por el señor, \& el señor } \\
\text { por el vasallo, \& cada vno de los amygos puede } \\
\text { rresponder por su amjgo quando es rreptado asi } \\
\text { commo delante se amuestra. Mas por omne que } \\
\text { fuese bjuo non puede otro njnguno rrebtar si non el } \\
\text { mjsmo porque el rriebto non deue ser rresçebjdo } \\
\text { personero fuera ende quando alguno quisiere rrebtr } \\
\text { a otro por su señor, o por muger, o por omne de } \\
\text { orden, o por tal que non pueda njn deue tomar } \\
\text { armas. Ca bien tenemos por derecho que el fecho } \\
\text { que en tales cayan puede rrebtar cada vno de sus } \\
\text { parientes maguer sea bjuo aquel por quien rriebta. } \\
\text { Pero dezimos que njngun traydor njn su fijo njn el } \\
\text { que fuese aleuoso non puede rreptar a otro njn } \\
\text { aquel que es judgado que fizo cosa porque vala } \\
\text { puedenos segunt costunbre de España. E otrosy non } \\
\text { njn el que sea desdicho por corte non pueda } \\
\text { njnguno rrebtar a aquel con quien ha tregua mjentra } \\
\text { durare, \& deuese fazer el rriebto ante el rrey, o por } \\
\text { corte, \& non ante rrico omne njn merino njn ante } \\
\text { acicial del rregno porque otro njnguno non ha } \\
\text { atro el fidalgo por traydor njn por el }\end{array}$ & $\begin{array}{l}\text { Reptar puede todo fidalgo por tuerto, o desonrra en } \\
\text { que caya traycion, o aleue, que le aya fecho otro } \\
\text { fidalgo. E esto puede fazer el por si mismo mientra } \\
\text { fuere biuo: e si fuere muerto, el que recibio la } \\
\text { deshonrra: puede reptar el padre por el fijo, o el fijo } \\
\text { por el padre, o el hermano por el hermano. E si } \\
\text { tales parientes non ouiere, puede lo fazer el mas } \\
\text { cercano pariente que fuere del muerto. E avn } \\
\text { puede reptar el vasallo por el señor: e el señor por } \\
\text { el vasallo, e cada vno de los amigos, puede, } \\
\text { responder por su amigo, quando es reptado, assi } \\
\text { como adelante se muestra. Mas por ome que } \\
\text { fuesse biuo, non puede otro ninguno reptar si non } \\
\text { el mismo: porque en el riepto non deue ser } \\
\text { recebido personero. Fueras ende, quando alguno } \\
\text { quisiere reptar a otro por su señor: o por muger, o } \\
\text { por ome de orden, o por tal que non deua, o que } \\
\text { non pueda tomar armas. Ca bien tenemos por } \\
\text { derecho, que en fecho que tales caya, pueda reptar } \\
\text { cada vno de sus patientes, maguer sea biuo aquel } \\
\text { por quien riepta. Pero dezimos, que ningund } \\
\text { traydor, nin su fijo, nin el que fuesse aleuoso, non } \\
\text { puede reptar a otro, nin aquel que es judgado } \\
\text { porque fizo cosa porque vala menos, segund } \\
\text { costunbre de España. Otrosi non puede reptar otro } \\
\text { ome que sea reptado, ante que sea quito del riepto, } \\
\text { nin el que se aya desdicho por corte, nin puede } \\
\text { ninguno reptar a aquel con quien ha tregua mientra } \\
\text { durare. E deuese fazer el riepto ante el Rey, e por } \\
\text { corte: e non ante rico ome, nin merino, nin otro } \\
\text { oficial del reyno, porque otro ninguno non ha poder } \\
\text { de dar al fidalgo por traydor, nin por aleuoso, nin } \\
\text { quitarlo del riepto, si non el Rey, tan solamente por } \\
\text { el } 19 r ; .3 .2 \text { ) }\end{array}$ \\
\hline
\end{tabular}

Salvo ligeros cambios, típicos de la copia de textos, el manuscrito de la BNE no parece extractar o resumir en nada lo que dice el texto de acuerdo con la edición de López. A pesar de ello, los redactores del Inventario general de manuscritos(13: 82) así lo declaran. Es más, entresacaron la lista de los fragmentos extractados:

ley IV a la XXII del tit. I; de la XXIX del tit. I a la II del VIII: leyes VII y VIII del tit. X: de la XI del tit. X a la XIV del tit. XV; de la XXVI del tit. XV a la VIII del tit. XXIX; de la V del tit. XXX hasta el fin de la Partida. 
Examinemos lo que dice la nota del Inventario. Que extracta desde 7.1.4 a 7.1.22; desde 7.1.29 a 7.8.2; las leyes 7.10.7 y 7.10.8; desde 7.10.11 hasta 7.15.14; desde 7.15.26 a 7.29.8 y desde 7.30.5 hasta el final. Cierto, eso es el texto que conserva, imprecisamente mencionado ya que el códice, en su estado actual, comienza con un poco de la parte final de 7.1.3:

quisieren sacar de la tierra contra defendimjento del rrey. Et el segundo es si alguno encubre, o furta tributos del rrey, o los derechos del rrey. Et el terçero es si alguno falssa moneda. Et el quarto es si alguno se trabaja de fazer yerro que tanxiesse a la persona del rrey o a perdimjento o a menoscabo de su señorio. o si lo fiziere por algunas de las rrazones que dexiemos en la terçera partida deste libro, en el titulo que fabla de los demandadores, ca estonçe bien puede acusar el sieruo, o la sierua non tan solamente a los estranos, mas avn a su señor mjsmo si oviere fecho alguno destos yerros. (BNE, MSS/8721, fol. 1r1)

Veamos qué sucede cuando el manuscrito llega a 7.1.22. El folio 7v2 acaba con "ante dezimos quel deue pecha el acusador aquello que rresçibjo del quarto doblado si gelo demandare”. Aparentemente tiene sentido y se podría creer que se ha extractado; la realidad es que el capítulo continúa, según López

...fasta vn año, e si despues del año gelo demandare, deuele pechar otro tanto quanto fue aquello que recibio del, como quier que el que es acusado, puede fazer auenencia sin pena sobre la acusacion, assi como de suso diximos. Pero el acusador, que la fizo cae en la pena que es puesta en la quinta ley ante desta. Esto es, porque desamparo la acusacion sin mandamiento del judgador. (López, 1555, 7ª Partida, fol. 11v).

La verdad es que ha perdido la parte final de la ley. Apoya esta afirmación el hecho de que el folio siguiente, el 8r, no comience con el texto de 7.1.29:

[T]estigos aduzen los omnes en sus pleitos para prouar o vençer lo que demandan Et despues que son rresçebidos los dichos dellos... (BNE, MSS/8721, fol. 8r1, líneas 5-9)

como afirman, sino con este otro pasaje:

...maguer non fuesen ende acusados njn demandados njn fuese aducha otra prueua contra ellos.

que coincide, palabra por palabra, con las últimas palabras de 7.1.28, según la edición de López:

...maguer que non fuessen ende acusados, nin denunciados, nin fuesse aducha otra prueua contra ellos. (López 1555, $7^{\text {a }}$ Partida, fol. 14v)

El siguiente grupo de leyes extractadas finaliza con 7.8.2 (fol. 23v2), en realidad con el comienzo de 7.8.3, lo que está claramente marcado por el espacio para insertar la rúbrica y la inicial de ley correspondiente:

[F]allando vn ome a otro que trauaua de su fija o de su hermana, o de su muger con quien estudiere casado segunt manda santa eglesia por yazer con ellas por fuerça... (BNE, MSS/8721, fol. 23v2)

Este bloque de extractos no es tan compacto con dan a entender, pues unos folios antes, en el $17 \mathrm{v}$, hay otro corte textual, que no debieron de detectar porque el fol. 17v2 acaba con un artículo, el, y en el fol. 18r1 la primera palabra es un sustantivo, casa. Es verdad que hay una discordancia gramatical, pero es sabido que a veces hay algunas discordancias de género entre el determinante y el sustantivo si lo consideramos desde el punto de vista de la lengua actual y quizá fue lo que pensaron los catalogadores. Sin embargo, la lectura detenida nos dice que nada tiene que ver lo que hay en el fol. 17v2:

[S] i en el primero dia el rrebtado o el rrebtador non fuere vençido en la noche ante si [espacio en blanco] quisieren, o el rrey lo mandare los fieles saquenlos del canpo \& métanlos amos en vna casa, \& faganles egualdat en el comer $\&$ en el beuer $\&$ en el yazer $\&$ en todas las otras gujsas. Pero si el vno quisiere mas comer o beuer que el otro dengelo el... (BNE, MSS/8721, fol. 17v2)

con lo que dicen las siete primeras líneas del fol. 18r1:

...casa atan ayna que fuese en culpa de la muger de aquel que con quien era ante casada asi commo en muchos lugares deste libro dixiemos en las leyes que fablan en esta rrazon. (BNE, MSS/8721, fol. 18r1) 
Lo cierto es que este último fragmento corresponde al final de 7.6.3, título que trata de la difamación — de los enfamados- y no de los rrieptos, que es el asunto del título 7.4., por lo que ha desaparecido la mitad de 7.4.5, todo 7.4.5, todo el título 7.5, y el proemio y las leyes 7.6.1, 7.6.2 y la mayor parte de 7.6.3.

Por otra parte, si se tratara de una copiada extractada, es decir, en la que se ha dejado solo lo esencial, es curioso que el final de algunas de las leyes encontremos remisiones y concordancias a otras leyes dentro de las Siete Partidas e incluso a otros textos legales como el Fuero Juzgo:

acuerda la quinta ley de adelante con esta $(7.1 .17$, fol. $5 \mathrm{v})$

en esta ley acuerda con la xxj ley que es en el titulo de las desonrras $(7.6 .8$, fol. $19 \mathrm{v})$

Et esta ley acuerda con el terçero libro en la postrimera ley del titulo de los escriuanos. Et otrosi acuerda con otra ley que es en el fuero judgo que es en el titulo seteno et comjença: si algunt omne faze falso scripto (7.7.6, fol. 21v2)

Et esta ley acuerda con la .xj. ley que es en el terçero libro, ques en el titulo segundo (7.10.7, fol. 24r)

Et esta ley acuerda con la vna ley del quarto libro que es en el titulo de los alogueros \& de los arrendamjentos (7.10.12, fol. $25 \mathrm{v}-26 \mathrm{r}$ )

Además, si quien examinó el códice para su catalogación hubiera prestado atención a la información extratextual que ofrece el códice, habría visto que cada cierto número de hojas, normalmente cada seis, hay una secuencia de letras en el margen inferior, a la derecha de la columna. Esa secuencia alfabética corresponde a la signatura de los seis primeros folios de cada cuaderno.

FIGURA 4

Signaturas de los folios 18-22, segundo cuaderno de BNE, MSS/8721

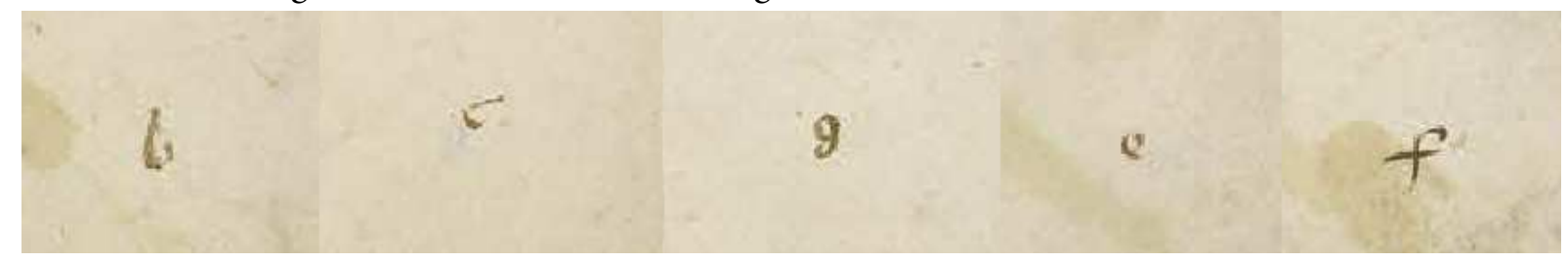

Esa secuencia no siempre está completa. Así, donde se produce el corte textual en el que comienza 7.1.29 (fol. 8r) podrían haber visto que en la esquina inferior derecha hay una b; en donde comienza 7.6.4 (fol. 18r) hay, de nuevo, una b en la esquina inferior. Solo en un lugar no hay pista alguna, pues donde comienza 7.10.6 (fol. 24r) es el último folio del cuaderno, como puede verse por el reclamo del fol. $24 \mathrm{v}$ —onrrado deue-, pero ahí les debería haber sorprendido que tras el reclamo hubiera, de nuevo, una letra $b$ en la esquina inferior derecha del folio 25r. Podría seguir abundando en estas pistas, pero no merece la pena alargarse.

Por consiguiente, esta aproximación permite establecer que el MSS/8721 de la BNE no es una copia extractada de la Séptima Partida, sino de una copia mutilada, que ha perdido a lo largo de su vida, pero siempre antes de la última encuadernación en el siglo XIX, dieciocho folios. ${ }^{7}$

\section{REFERENCIAS}

BETA = Faulhaber, Charles B. (dir.) (1997-). Bibliografía Española de Textos Antiguos. Berkeley: The Bancroft Library, University of California. Recuperado de https://bancroft.berkeley.edu/philobiblon/beta_en.html

Blecua, A. (1983). Manual de critica textual. Madrid: Castalia.

Bofarull y Sans, F. de A. de (1910). Los animales en las marcas del papel. Villanueva y Geltrú: Oliva.

Chiesa, P. (2012). Elementi di critica testuale. Bolonio: Pàtron.

Craddock, J. (1981). La cronología relativa de las obras legislativas de Alfonso X el Sabio, Anuario de Historia del Derecho Español, 51, 365-418.

Craddock, J. (1986). The Legislative works of Alfonso el Sabio: A critical bibliography. Londres: Grant \& Cutler. 
Domínguez Bordona, J. (1933) Manuscritos con pinturas. Madrid: Centro de Estudios Históricos.

Fradejas Rueda, J. M. (2021). Los testimonios castellanos de las Siete Partidas. En J. M. Fradejas, R. Pichel y E. Jerez (Eds.), Las "Siete Partidas" del Rey Sabio: una aproximación desde la filologia digital y material (pp. 21-35). Madrid / Frankfurt am Main: Iberoamericana / Vervuert.

Gómez Redondo, F. y Lucía Megías, J. M. (2002). "Las Siete Partidas”. En C. Alvar y J. M. Lucía Megías (Eds.) (pp. 15-27). Madrid: Castalia.

Herriot, H. (1952). "The Ten Senses in the Siete Partidas". Hispanic Review, 20(4), 269-281.

Inventario (1995). Inventario general de manuscritos de la Biblioteca Nacional. XIII (8500 a 9500). Madrid: Biblioteca Nacional.

López, G. (2020), “López 1555, Séptima Partida”, transcripción de J. Martín Álvarez. En J. M. Fradejas Rueda (Ed.), 7PartidasDigital, https://7partidas.hypotheses.org/8559.

Paz y Melia, A. (1904). Códices más notables de la Biblioteca Nacional: XI, Revista de Archivos, Bibliotecas y Museos, $40,437-440$

Pérez López, J. L. (1996), Las Siete Partidas según el códice de los Reyes Católicos de la Biblioteca Nacional de Madrid, Dicenda. Cuadernos de Filología Hispánica, 14, 235-258.

Sánchez-Arcilla Bernal, J. (Ed.). Alfonso X, el Sabio (2004). Las Siete Partidas (El libro del fuero de las leyes). Madrid: Reus.

Stussi, A. (1994). Introduzione agli studi di filologia italiana. Bolonia: Mulino.

Stussi, A. (1998). Fondamenti di critica testuale. Bolonia: Molino.

\section{Notas}

1 Este trabajo forma parte de los resultados del proyecto 7PartidasDigital (referencias FFI-2016-75014 y PID2020-112621GB-I00) cuyo objetivo es la Edición crítica digital de las Siete Partidas. Este proyecto https://7parti das.hypotheses.org se desarrolla desde la Universidad de Valladolid, cuenta con la financiación de la Agencia Estatal de Investigación del Reino de España y se integra dentro de la Red de Excelencia 'Cultura escrita medieval hispánica: del manuscrito al soporte digital (CEMH)' (RED2018-102330-T). Agencia Estatal de Investigación. Ministerio de Ciencia e Innovación.

2 Según Blecua (1983, p. 38), los testimonios indirectos son "citas de autores, fragmentos en antologías, en refundiciones, en traducciones, etc.", que es lo mismo que sostienen Stussi (1994, p. 86 y 1998, p. 9, n. 4) o Chiesa (2012, p. 35 y pp. 105-107).

3 Se citan todos los testimonios de las Siete Partidas por medio del sistema de siglas establecido en 7PartidasDigital. Para una tabla completa de las mismas véase Fradejas Rueda, 2021.

4 Hay varios casos más. Uno se encuentra en el ms. 28-15 de la Biblioteca de la Catedral de Toledo (= TFA), que recoge tres leyes del undécimo título de la Tercera Partida (3.11.19-21) en un quinión cuyos primeros cinco folios están en blanco. Otro caso interesante es el manuscrito Reservado 125 de la BNE (= MNZ), en el que en las dos últimas hojas (fols. 90-91) del último de los tres cuadernos que contienen el Tratado de armas de Diego de Valera (fols. 54r-86r) alguien copió el título de los infamados (7.6). Un tercer caso dentro de esta categoría es la copia que aparece en el vuelto del folio de guarda (o de portada) del ms. 248 de la BNE (= MNX). En ese vuelto se copiaron las leyes 1.2.7 y 1.2.8, esta última incompleta, que tratan de qué es fuero y cómo se hace un fuero en un volumen que recoge una copia del Fuero de Navarra (según el tejuelo del manuscrito es el Fuero de Sobrarbe). En el Archivo Histórico de la Nobleza (Cifuentes, $\mathrm{C} 2, \mathrm{D} 7 \mathrm{TN} 1)$ se conserva un cuarto testimonio de este tipo puesto que se trata de la copia de 2.9.16, referente al oficio de Alférez Mayor del Rey.

5 La bibliografía sobre este códice, que no fue conocido por los editores de la Real Academia de la Historia, comienza con la primera descripción es la de Paz y Melia (1904, pp. 437-440) y noventa y dos años más tarde se publicaron los paratextos, tablas de títulos y los prólogos (Pérez López, 1996). Craddock, 1981 (393n48) y 1986 (52-53) y Pérez López (1996, p. 239, n. 27) ofrecen las referencias bibliográficas sobre este códice.

6 Pérez López (1996, pp. 243-244) mencionó esta aparente error, pero solo aclara que la tabla no solo recoge el contenido de la Segunda Partida, sino también de todas las demás, aunque es ligeramente inexacto puesto que esa tabla no incluye los títulos de la Primera Partida. Este no es él único error que ha padecido este códice. Domínguez Bordonada (1933, p. 
340, n 873) le asignó la signatura Vit. 2-8, lo que provocó que Herriott (1952, p. 269) creyera que era el desaparecido BR3 (X-131 de la BNE, hoy en la Biblioteca Zabálburu).

7 Contrariamente a lo que afirman Gómez Redondo y Lucía Megías (2002, p. 25), en este volumen no hay ningún texto latino. Tras el texto de la Séptima Partida hay cinco breves párrafos de corte legal, de los que el primero corresponde a la ley 5.6.1. del Espéculo alfonsí y el último es un juramento que han de pronunciar los judíos al comienzo de un interrogatorio judicial. 